\title{
Overstock - A Real Option Approach
}

\author{
Rui Fernandes \\ Aveiro University \\ rfernandes.ar@amorim.com \\ Joaquim B. Gouveia \\ Carlos Pinho \\ Aveiro University \\ cpinho@ua.pt
}

\begin{abstract}
In the last decades, firms have been facing a new challenge, considering the increasing uncertainty of the markets and the pressure to achieve better levels of performance, within the stake-holders expectations. Three main problems have been emerging in dealing with management performance: the increasing pressure to reduce working capital, the growing variety of products and the fulfillment of a demanding service level. Most of the popular indicators have been developed based on a controlled environment. A new indicator is now proposed, based on the uncertainty of the demand, the flexibility of the supply chains, the evolution of the products lifecycle and the fulfillment of a required service level. The model to support the indicator will be developed within the real options approach.
\end{abstract}

Keywords: overstock, stock management, real options, supply chain

\section{INTRODUCTION}

Stocks levels depend on the internal management capacity and flexibility, which is easier to attain than to deal with unpredictable clients or powerful suppliers (outside partners). The pressure has been focusing on the stocks levels and oblige managers to think in a different way.

For Katz (2006), the inventory is perceived as a bad management practice, once the associated costs tend to be very relevant for the firm profit and loss statement.

Capital management is a task assigned to the financial department, which understands stock as a way to slow the cash flow and a very risky decision. It is difficult to decide whether to have or not stock, mainly when the causes that provoke the buffer, in certain levels of the supply chain, are not clearly understood.

Traditionally, managers tend to analyze stock risk using the turnover index. This metric gives a gen- eral idea of the potential problems, but makes the communication between financial and supply chain managers more difficult. Even the storage time approach, as a more recent key indicator, going deeply in the analysis of stock aging, cannot solve the gap of communication between finance and logistics, as it focuses mainly on the past and historical data.

But why do companies need inventory? Following Silver, Pyke and Peterson (1998) orientation, the reasons for stock existence are: allow independency between operations; minimize the impacts of demand variability across the supply chain; allow flexibility in the resources planning of the supply chain; protect from delays of supplier lead-times and use favorable purchase conditions based on big batch, but also because of the standardization of input components.

Also Joseph, Larrain and Singh (2008) defined some reasons that justify the existence of stock: to improve 
production scheduling, smooth production, minimize stock-out costs, speculate or hedge about prices, reduce purchasing costs by buying large quantities (rappel effect) and to shorten the delivery days (improve service level).

Besides these authors, also Wiersema (2008) reinforced the need of inventory based on a main cause: the difficulty in obtaining the items.

Despite the presented authors' opinions, defending the existence of stocks, the main reason of their existence is the need to guarantee a certain service level.

The use of excess of stock, or overcapacity available, or too high lead-times or even the "over" planning, can be seen as internal corrective or preventive actions to avoid, or to compensate, the poor customer service level perceived from the exterior of the chain (Forslund \& Jonsson, 2007).

Besides the traditional financial perspective about the negative impact on invested capital, stocks allow shorter lead-times in a competitive market and manage customer strategy and service, avoiding the negative answer to a request (delays).

\section{LITERATURE REVIEW}

Most of the studies done pointed the sourcing flexibility as a way to deal with the uncertainty from the demand side. For Antanies (2002), the performance of the working capital must be solved considering the impact of uncertainty of demand in the level of inventory, using a vendor management inventory system combined with components of the products. For Jian and Ma. (2004) and Forslund et al. (2007), the way to deal with demand uncertainty is based on the definition of parameters of the safety stock. Hadley (2004), presented two perspectives in inventory management: the cycle inventory and the safety inventory. Tan (2008), considered that the safety stocks are kept to minimize the forecast mistakes. Borgonovo and Peccati (2007) pointed a sensitivity analysis to deal with uncertainty, also based on the input parameters of the traditional models. For Lapide (2008), the way to deal with uncertainty is by increasing the number of buffers, using the variability buffering law (inventory, capacity, time).

Despite the improvements done on traditional safety stock, the demand is assumed as being deterministic. However, some studies have pointed a stochastic approach, which of the most common are: the base stock model, stochastic multi-echelon systems and strategic safety stock. The main assumptions of these approaches are based on the fact that there are no fixed costs and on the trade-off decision between assuming holding inventory costs and stock-out costs.

The base stock model, with demand uncertainty, is based on the assumption that excess inventories implie holding costs, unmet demand is backordered, which represents a certain cost and is applied for a single echelon. According to Song (2008), a prioritized base-stock policy can be used to control the production to meet exogenous Poisson demands. He used a matrix analytical method.

The multi-echelon systems are based on the definition of a stock level in each stage of a chain, using the net-lead-time. Pearson (2003) presented an equilibrium solution to the two-echelon problem. Bollapragada, Rao and Zhang (2004) introduced a new concept: the cost weighted stock levels.

The study of Graves and Willems (2000) points the strategic safety stock as way to optimize the inventory levels, modeled as a spanning tree under uncertain demand. Schmit (2008) made a reference to over-stock inventory (cycle stock plus safety stock). Workman and Scheidler (2009) has pointed three classifications for the safety stock: safety stock demand, supply and strategic.

To solve the problem of uncertainty, Tan et al. (2009) proposed, applying for Monte Carlo simulation, the use of a reserved stock to prospective future demand, based on customer preference classification.

Sodhi, ManMohan and Tang (2009) proposed to extend the linear programming model of deterministic supply-chain planning, to take demand uncertainty and cash flows into account for the medium term.

Moole and Korrapati (2004) stated that the way to deal with uncertainty is getting and working data (decision support system). Also Sheffi (2001) stated that the share of information along the chain can improve the reaction to demand uncertainty. Tan (2007) defended the forecasting methods advance demand information. Based on the rolling horizon flexibility, Walsh, Williams and Heavey (2007) examined the way to minimize the impact of demand uncertainty, in a discrete event simulation model, and Matuyama, Sumita and Wakayama (2009) defended the forecast systems improvements. Ryu, Seung-Jin, Tsukishima and Onari (2009) add the importance of sharing information between players (Ferrer and Whybark, 2001). 
Lusa, Corominas and Muñoz (2008) used a multistage stochastic optimization model in the study of the relation between the resources planning optimization and the demand uncertainty. For Mukhopadhyay and Ma (2009), there are two ways to deal with the demand uncertainty: by flexibility in sourcing or adjusting the yield rate of the internal production resources.

For Marvel and Wang (2007) and Bish, Liu and Suwandechochai (2009), the manufacturer can avoid the impact of demand uncertainty by developing a better ordering prioritization system from the retailer. Graman (2010) split demand into two parts: predicted demand and non predicted demand. The paper presented by Handfield, Warsing and $\mathrm{Wu}$ (2009) introduced the concept of penalty costs for orders not fulfilled. Song, Jing-Sheng, Zhang, Hou and Wang (2010) presented the reorder point and order quantity, based on optimal policy parameters to deal with demand uncertainty but limited to one single item, which, according to Hemmelmayr, Doerner, Hartl and Savelsbergh (2010), does not consider the relevant product mix uncertainty.

\section{REAL OPTIONS}

The origin of the term "real option" goes back to 1977 and was coined by professor Stewart Myers (1977), and was later popularized by Michael Mauboussin, who used the concept to explain the gap between business intrinsic value and market value. Gertner and Rosenfield (1999) defined real options as a method to value opportunities associated with the possibility of changing decisions in order to solve uncertainty. The traditional discounted cash flow technique cannot count with this uncertainty. Compared to the financial options, real options demand active reaction of the management team. Real options can be seen as a mechanism to support the decision process and as a way to value managers' team flexibility. The potential value is not a tangible asset neither a trade underlying asset in liquid markets. Considering this fact, real options have no market price (there is no capacity to estimate the future unit price as there is no forward price market) (Boyer, Christoffersen, Lasserre \& Pavlov, 2003).

\section{OVERSTOCK AS A REAL OPTION}

When a company faces a stochastic demand, in scale and mix, one requires an efficient resources management, also as the adaptation to restrictions in the capacity of the supply chain, according to the required volume and time. In this situation, managers should choose options that are able to minimize the risk of inventory and the risk of not having the item available in face of a demand manifestation.

The evolution done in the past, applying for shorter lead-times, shorter invested capital and shorter costs, changed the supply chain in order to become leaner. But, since September 11th 2001, a new feeling of uncertainty rose and is changing the form of managing the supply chain. The physical flow of materials depends on the availability of infrastructures (from the firm, the suppliers and the public global providers). Dual source strategies rise to minimize the risk associated with a disruption. Companies complement the "just in time" concept with the "just in case" concept (Sheffi, 2001), which means a revaluation of the need of safety stock, both on source and client delivery. The planning should change from a push centralized strategy to a pull market oriented strategy (Sengupta, 2004). This explains the need of changing the tools that support the stock management, from a historical data support to a data based forecast, within limitations of resources and minimizing the risk.

Most applications of the term overstock were related to excess of stock. In 2007, new approaches were done introducing the concept of obsolescence cost (Emsermann \& Simon, 2007) and overstock risk (Jia-zhen, Jian-jun \& Jin, 2007). Recently, Ding and Chen. (2008) made an approach to overstock, considering it as an avoidable and shared loss between supply chain players.

\subsection{Model Assumptions}

Considering an installed capacity and restrictions in the use of an outsource option, it is possible to assign an overstock option value to inventory. This means the use of an option to increase stock above a maximum position. This option should be based on demand uncertainty, in quantity and mix, to allow risk minimization of a negative response to a client request. Overstock option allows risk minimization of product stock-out, for which the company assumes a lead time, and it forces the minimization of the out-of-mix stock risk for excessive inventory. It was proved by Schmit (2008), that there is a relation between supply uncertainty and inventory level and, for Stalk (2008), the inventory level must be linked with scale and product portfolio. The uncertainty affects the demand (as a stochastic process) but also the combination of items (as a logistic basic unit part) - this is what we can call "the mix effect". 
In the present model, overstock is defined as the excess of stock above maximum stock. This excess allows the minimization of lost sales risk, due to restrictions in the available capacity of the supply chain or of the driver resources. To apply this concept, an item classification is required, changing the traditional "ABC" perspective, to a more complex classification, regarding the actual context of uncertainty, like the mix variety and diversity, products lifecycle decrease and the consequent innovation process increase. Considering these arguments, products should not be treated in the same way.

\subsection{Items Classification}

"A's" is the terminology for those items representing more than $80 \%$ of the gross sales value. These items can follow a make to stock procedure, depending on the existing push or pull strategy. They can be called as fast movers. "B's" for items that fulfill the gross sales value gap between $80 \%$ and $95 \%$. They can follow an assembly to order procedure, based on available components, in a stage where standardization is possible. They can be defined as movers. These items should be storable using sales forecast, with low risk. " $C^{\prime} s$ " is the name for the items with a low rotation. They are used to promote sales of A's or B's items (mix attraction); that is why there should be small batch quantities in stock. They can be identified as slow movers. "Sp's" for those items that are assigned to one client or market segment, nevertheless the use of a specific or shared distribution channel. The stock risk tends to infinity. We can define them as specific products (niche oriented). "N's" is the name for the new items. They are identified as new products or phase-in products. There's a high risk exposure. "P's" is the designation of the items that are in the maturity stage. In this stage, there should be a preparation of the tools to allow a minimum phasing-out cost. For these items, risk is a variable with high probability to occur. They are known as products with potential risk. O's for the items in the "death" stage. For these items, the risk is a constant.

\subsection{Overstock Calculation}

Overstock should be calculated by item group, using the previous classifications (A, B, C, S, N, P and O).

Definition of variables: Lead Time definition in weeks $=L_{t}$; Sales historical value for $\mathrm{n}$ weeks $=\mathrm{Vn}$; Variance coefficient $=\alpha$ (depending on the item category); Number of weeks $=$ n; Actual stock value $=$ S; Actual book of orders value for $n$ weeks $=\delta n$; Sales value forecast for $\mathrm{n}$ weeks $=\beta \mathrm{n}$ and Profit margin (sales unit price - stock unit cost $) /$ sales unit price $=\theta$ p. $($ Table 1$)$

\section{Table 1 - Overstock expression}

\begin{tabular}{|c|c|}
\hline Item classification & Overstock expression \\
\hline $\mathrm{A}$ and $\mathrm{B}$ & $\sum_{i=1}^{i=n} L_{i} \cdot \alpha_{\boldsymbol{B}} \cdot \frac{\beta n_{i}}{n} \cdot\left(1-\theta p_{i}\right)-\sum_{i=1}^{i=n} S_{i} ; i=A_{1} \ldots A_{n} ; B_{1} \ldots B_{n}$ \\
\hline $\mathrm{C}$ and $\mathrm{Sp}$ & $\sum_{i=1}^{i=n} L_{i} \cdot \alpha_{C S p} \cdot \frac{\delta n_{i}}{n} \cdot\left(1-\theta p_{i}\right)-\sum_{i=1}^{i=n} S_{i} ; i=C_{1} \ldots C_{n} ; \boldsymbol{S}_{1} \ldots \boldsymbol{S}_{n}$ \\
\hline $\mathrm{N}$ & $\sum_{i=1}^{i=n} L_{t} \cdot \alpha_{N} \cdot \frac{\beta n_{i}}{n} \cdot\left(1-\theta p_{i}\right)-\sum_{i=1}^{i=n} S_{i} ; i=N_{1} \ldots N_{n}$ \\
\hline $\mathrm{P}$ and $\mathrm{O}$ & $\sum_{i=1}^{i=n} L_{t} \cdot \alpha_{B} \cdot \frac{\not \boldsymbol{H}_{i}}{n} \cdot\left(1-\theta p_{i}\right)-\sum_{i=1}^{i=n} S_{i} ; i=P_{1} \ldots P_{n} ; O_{1} \ldots O_{n} ; L_{i}=\mathrm{O}$ \\
\hline
\end{tabular}

\subsection{Modeling Overstock As A Real Option}

Main assumptions of the model: the items classification is an auxiliary process, the information of the output of this process depends only on the firm, the stocks refer only to manufactured items and the demand (quantity) is a stochastic variable (the firm does not have any influence on quantity and sales price - is a price taker).
Basic assumptions of the model: the products can be analyzed individually, according to a defined classification; any demand not fulfilled from stock is lost at moment $t$, the lead times are fixed and known and one does not consider the impact of lost market share in period $t+1$ due to a disruption in near time $t$.

Main question of the model: What is the optimal value of the overstock in time " $t$ " (option value)? 


\subsection{Valuing The Flexibility}

The decision is about the level of overstock value (stock above the previous existing level). For the model are important a cost function and eventually the capacity constraints, as this is the limitation for future orders fulfillment. The model will not consider efficiency in the use of the available resources (this issue should be treated in the manufacturing flexibility). The capacity constraints will not be considered. We assume it is not relevant to the decision process. The overstock value should be calculated according to each product classification. The classification will be done considering the product lifecycle and will be treated as an independent auxiliary process.

\subsection{Source of Uncertainty}

The source of uncertainty is the demand (quantity), which we are going to represent by " $\mathrm{D}$ ". Company cannot influence the sales price with the level of overstock. The possibility of having available material to deliver will not change the sales price behavior. The evolution of the demand is the most important input for the option valuation. We assume that the demand of each product category is stochastic and follows a geometric Brownian motion (assumption done also by Pindyck (1988); Tannous (1996); Bengtsson (2001)). The demand process can be presented as:

$\mathrm{dD}=\alpha \mathrm{Ddt}+\sigma \mathrm{Ddz}$

Where $\mathrm{dz}=\in(t) \sqrt{t} ; \mathrm{E}(\mathrm{t}) \approx \mathrm{N}(0,1) ; \alpha=$ instantaneous drift; $\sigma=$ volatility; $\mathrm{dz}=$ increment of a winner process; where $E(t)$ is a serially uncorrelated and normally distributed random variable.

From equation (1) we can state that demand (D) is log-normally distributed with a variance that grows with the time horizon (also an assumption of the model presented by Bengtsson (2001)). The demand is modeled as a continuous process. We assume that all the production and stock policy is make-to-stock.

\subsection{Decision Rules and Payoff}

Variables meaning: $h=$ stock aging factor; $D=$ demand in quantity for the item category; ${ }^{c_{v}}=$ variable production cost of a single unit; $\mathrm{pv}=$ unit sales price; $1-\mathrm{S}=$ stockout rate for item class; $\mathrm{K}=$ value calculat- ed as a function of the stockout rate (normal distribution); $\mathrm{S}=$ required service level for item category: $\%$ of the quantity fulfilled on the required date; Lt $=$ lead time definition; $\mathrm{j}=$ Weighted average cost of capital, reported and adjusted to period $t$ (simplification); $\theta=$ average stock unit cost; $I_{t-1}=$ existing inventory level in the beginning of period $n ; n$ $=$ period $\mathrm{n}$ (between $\mathrm{t}-1$ and $\mathrm{t}) ; \mathrm{Mv}=(\mathrm{pv}-\mathrm{cv}) . \mathrm{D} ; n$ $=$ period $\mathrm{n}$ (between $\mathrm{t}-1$ and $\mathrm{t}$ ); ${ }^{k_{s}}=$ cost of holding stocks for each item for period $(t-1 \stackrel{\text { ↔ }}{\longleftrightarrow})$.

If we study one overstock option, which expires at time $t$, and gives us the option to adjust the stock level, and if the benefits exceed the costs for changing the stock level, respecting the maximum allowed capital, the value of the option at time $t(\Omega(t))$ can be written as:

$D \cdot \theta \cdot L_{t} \cdot K\left(1-j-h-\frac{k_{s}}{\theta}\right)-M_{v}(1-S)-I_{t-1}$

The value of the overstock option is the expected terminal value of the condition:

$\Omega(t)=\max \left[D \cdot \theta \cdot L_{t} \cdot K\left(1-j-h-\frac{k_{s}}{\theta}\right)-M_{v}(1-S)-I_{t-1}, 0\right](3)$

Where " $D \cdot \theta \cdot L_{t} \cdot K$ " represents the stock allowed using the traditional approach; " $M_{v}(1-S)$ " represents the loss margin related to sales not fulfilled on time and " $j+h+\frac{k_{s}}{\theta}$ " represents the opportunity cost of the invested capital, the risk of obsolescence and the weight of the holding costs on the average stock unit cost.

$0 \leq \Omega(t) \leq C^{t}$

$C^{t}=$ maximum invested capital value allowed in stocks for time $t$.

In this form, the overstock can be expressed as a European call option, where $D \cdot \theta \cdot L_{t} \cdot K\left(1-j-h-\frac{k_{s}}{\theta}\right)-M_{v}(1-S)$ 
value of the underlying asset (A). The actual stock level $I_{t-1}$ can be treated as the exercise price (E). An overstock manufacturing order should take place if $\Omega(t) \geq 0$. The overstock option gives the right to increase stock level above the existing one, for each product category, and expires in time $t$.

Boundary conditions:

Absorbing barrier: 0; when $\Omega(t) \leq 0$

Expiration optimal condition:

$\max \left[D \cdot \theta \cdot L_{t} \cdot K\left(1-j-h-\frac{k_{s}}{\theta}\right)-M_{v}(1-S)-I_{t-1}, 0\right]$

Value matching at $\Omega^{*}(t)$ (optimal overstock level) :

$D \cdot \theta \cdot L_{t} \cdot K\left(1-j-h-\frac{k_{s}}{\theta}\right)-M_{v}(1-S)-I_{t-1}$

\subsection{Valuing the Option}

The value of an overstock option, at time $t$, must satisfy the following differential equation:

$$
\alpha . D \cdot \frac{d \Omega}{\not D}+\frac{1}{2} \cdot \sigma^{2} \frac{d \Omega^{2}}{d^{2} D}-r \Omega=0
$$

\subsection{Valuation Model: Numerical Example}

The numerical example chosen is about the application of the concept within a flooring industrial company. The company works with different product categories. We are going to apply the concept to one of the portfolio categories. The company analyzes the performance of stocks management based on historical data. But, considering the volatility of the demand distribution, of more than $20 \%$, the firm needs to anticipate the stocks level to avoid disruptions. The problem is how to anticipate within a certain required level of performance. The demand is considered a stochastic variable. Demand volatility assumption $=0.25$. $($ Table 2$)$

Table 2: Parameters value for the numerical example

\begin{tabular}{|lll|l|}
\hline Factor & Description & Value & Unit \\
\hline $\mathrm{D}$ & demand quantity & 262,051 & $\mathrm{~m}^{2} / \mathrm{month}$ \\
$\mathrm{I}_{\mathrm{t}-1}$ & stock value at the beginning of period & $4,849,145$ & euros \\
$\mathrm{h}$ & stock aging factor & 0.002 & coefficient \\
$\mathrm{c}_{\mathrm{v}}$ & variable production cost of a single unit & 5.000 & $€ / \mathrm{sku}$ \\
$\mathrm{p}_{\mathrm{v}}$ & unit sales price & 15.000 & $€ / \mathrm{sku}$ \\
$\mathrm{S}$ & required service level & $95.0 \%$ & $\%$ \\
$\mathrm{j}$ & Weighted average cost of capital & $0.5 \%$ & $\% / \mathrm{month}$ \\
$\mathrm{L}_{\mathrm{t}}$ & Lead time definition & 1.5 & $\mathrm{months}$ \\
$\mathrm{k}_{\mathrm{s}}$ & holding stock cost/unit for the period & 0.263 & $€ / \mathrm{sku} / \mathrm{month}$ \\
$\theta$ & average stock unit cost & 7.500 & $€ / \mathrm{sku}$ \\
\hline
\end{tabular}

Results of the model

$\Omega \mathrm{t}=$ Overstock value (option value) $=323,714$ euros .

The impact on the stocks level due to the introduction of a stochastic variable will be analyzed. The first approach will be the analysis of the impact of the growth of the demand on the overstock value, for different volatility parameters. 
Figure 1: Demand quantity variation, demand volatility and the overstock value

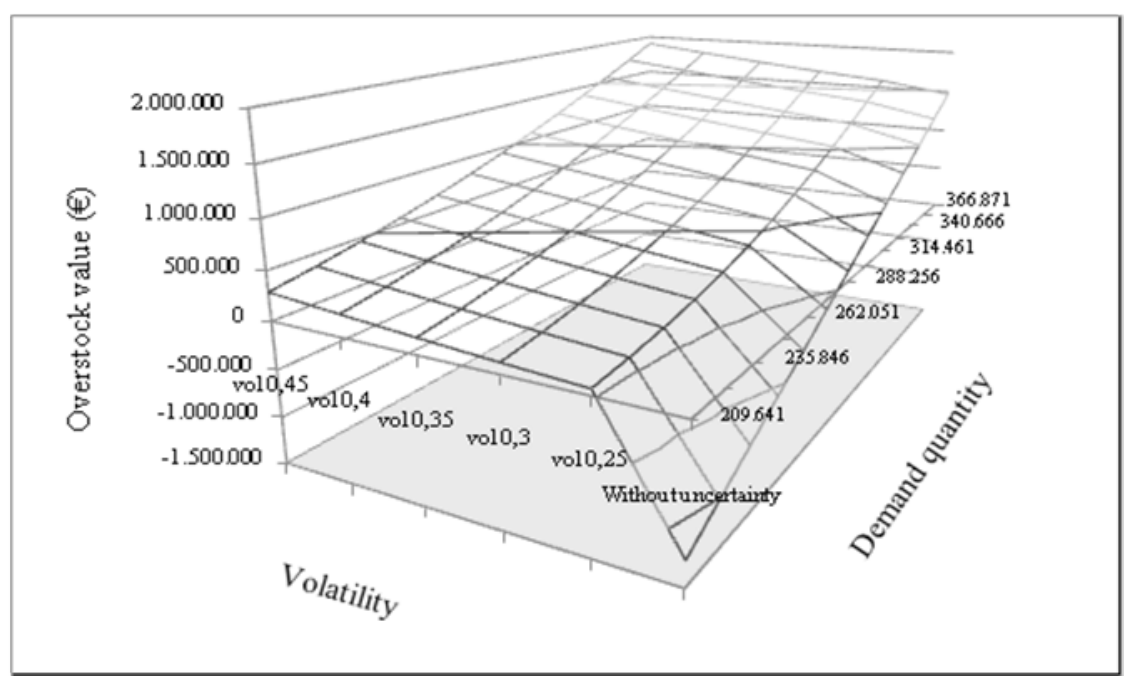

The elasticity between overstock value and demand quantity is stated on the graph (Figure 1). For an environment without uncertainty, the overstock concept, when negative, states for an excess in the existing stock value. The value of the overstock in both situations - with and without uncertainty - increases as quantities increase. In an environment with uncertainty, as the volatility increases, the required overstock value increases, in order to guarantee the assumptions of the model. For a lower demand uncertainty, the overstock tends to zero.

Figure 2: Lead time, demand volatility and the overstock value

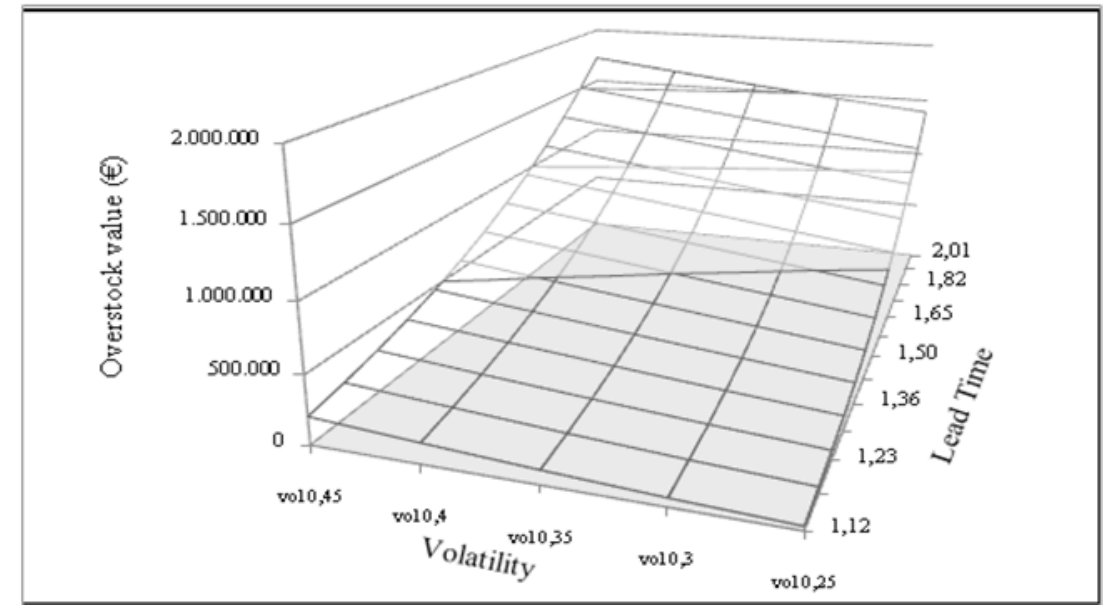

When the lead time increases there is an additional need of time to answer for a request. This period of time demands a high level of stock to buffer the gap between the output time of the physical flow and the orders date (Figure 2). 
Figure 3: Obsolescence rate, demand volatility and the overstock value

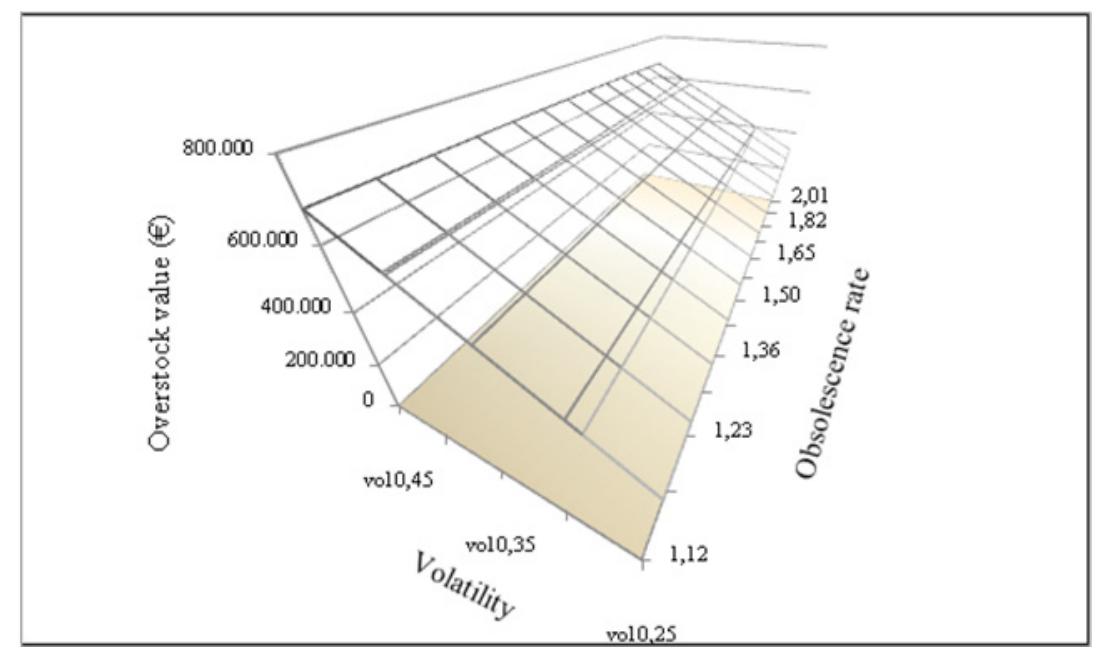

The obsolescence rate states for the average stock that can go through a phaseout stage in a short period of time. There is a high risk perception. For this reason, the overstock allowed decreases as this rate increases. To avoid more risk, the firm must develop the activities to support the phase out process in a proper way (Figure 3).

\section{CONCLUSIONS}

The goal of this study was the determination of the overstock level allowed, to satisfy the service level requirements as also the adequacy of the invested capital on stocks. The common way to analyze stocks is based on historical data and treats all the items in the same way, not respecting the products lifecycle evolution.

The numerical models normally used do not adapt to changes in the demand, because they tend to follow past tendencies. In this way, overstock comes as an alternative tool for stocks management. The calculation of the adjusted overstock level can be supported by on the real options approach, mainly based on two drivers: the demand - as an uncertainty variable input, and the overstock - as a flexible indicator within the supply chain. In the overstock decision process, there is a relationship between the increase of the uncertainty and the need to increase the stocks' value. The model also states that, in the absence of uncertainty, the stocks level can be calculated by the traditional formula, which means no overstock. If there is no flexibility in management, the stock value is influenced by a conditional parameter which can also have the same result as using the traditional approach.
When applying the real options approach (REOPA) to the overstock calculation, we can understand the influence of the demand's volatility on the invested capital, also as the impact of the lead times and service level definitions. The use of the real options approach has been associated with the measurement of value due to the flexibility within uncertainty environments. The REOPA is a way to support the decision process, in order to maximize the required value improvement.

The contribution of this work is the enlargement of the tools used for stocks management, respecting the actual need of future oriented based decisions, as a consequence of the increasing in the uncertainty of the markets, also as the need to account for the product lifecycle evolution. It was proved that the overstock level can be calculated and used, and there is an optimal value to be fulfilled. The existence of a link between the demand quantity and volatility with the stock value was also proved; the lead-time and service level definitions and the product lifecycle impact, based on the use of the obsolescence factor was also studied.

The model was aimed to introduce the volatility of the demand on the stock value calculation. Nevertheless, there is also an important impact of the items classification, as it can give a better view about the study of the best process to apply for the demand's behavior. A future application of the concept can count with an additional and more elaborated level of uncertainty, based on the products lifecycle evolution. The lifecycle evolution can influence directly the lead times and the service level definitions. There should also be considered the im- 
pact of the capacity constraints, along the chain, as an uncertainty source. The overstock value can also help managers in smoothing the resources used, allowing an increase in the relation between effectiveness and costs.

\section{REFERENCES}

Antanies, J. (2002), "Recognizing the effects of uncertainty to achieved working capital efficiency", Pulp \& Paper. San Francisco, Vol. 76, Iss. 7, pp. 46, 4 pgs.

Bengtsson, J. (2001), “Manufacturing flexibility and real options", Department of Production Economics, IMIE, Linköping Institute of Technology, S-581 83, Linköping, Sweden.

Bish, E.; Liu, J. and Suwandechochai, R.(2009), “Optimal Capacity, Product Substitution, Linear Demand Models, and Uncertainty", The Engineering Economist. Norcross: Apr-Jun, Vol. 54, Iss. 2, pp. 109.

Bollapragada, R.; Rao, U.S. and Zhang, J. (2004), “ Managing two-stage serial inventory systems under demand and supply uncertainty and customer service level requirements", IIE Transactions, 36, pp.73-85.

Borgonovo, E. and Peccati, L. (2007), “Global sensitivity analysis in inventory management ", International Journal of Production Economics. Amsterdam, Jul, Vol. 108, Iss. 1/2, pp. 302.

Boyer, M.; Christoffersen, P.; Lasserre, P. and Pavlov, A. (2003), "Value Creation, Risk Management, and Real Options", CIRANO, Université de Montréal, McGill University, UQÀM, Simon Fraser University.

Chase R., Jacobs F., Aquilano N. (2006), “Operations Management for competitive advantage", 11 th edition. McGraw Hill, pp 589-625.

Ding, D. and Chen, J. (2008), “Coordinating a three level supply chain with flexible return policies", Omega, Oxford, Vol. 36, Iss. 5, Oct, pp. 865.

Emsermann, M. and Simon, B. (2007), “Optimal Control of an Inventory with Simultaneous Obsolescence", Interfaces. Linthicum, Sep/Oct, Vol. 37, Iss. 5, p. 445 (12 pages).

Ferrer, G; Whybark, D. Clay (2001) “Material Planning for a Remanufacturing Facility", POM.

Forslund, H. and Jonsson, P. (2007), "The impact of forecast information quality on supply chain performance", International Journal of Operations \& Production Management, vol 27, n 1, pp. 90-107, 98-104.

Gertner, R.; Rosenfield, A. (1999), "How real options lead to better decisions; [Surveys edition]" Financial Times. London (UK): Oct 25, p. 06.

Graman,G. A. (2010), “A partial-postponement decision cost model", European Journal of Operational Research, Amsterdam, Feb 16, Vol. 201, Iss. 1; pp. 34.

Graves, S. C.; Willems, S. P. (2000), “Optimizing strategic stock placement in supply chains", Manufacturing \& Service Operations Management, Informs, Vol 2, № 1, Winter, pp 68-83.
Hadley, S. W. (2004), "A Modern View of Inventory", Strategic Finance. Montvale, Vol. 86, Iss. 1, p.30,6pgs.

Hemmelmayr, V.; Doerner, K. F.; Hartl, R. F. and Savelsbergh, Martin WP (2010), "Vendor managed inventory for environments with stochastic product usage", European Journal of Operational Research, Amsterdam, May 1, Vol. 202, Iss. 3, pp. 686.

Handfield, R.; Warsing, D. and Wu, X. (2009), “ (Q,r) Inventory policies in a fuzzy uncertain supply chain environment", European Journal of Operational Research, Amsterdam, Sep 1, Vol. 197, Iss. 2, pp. 609.

Jian, L. and Ma, S. (2004), "Research on values of safety factor coordination under random supply", International Journal of Services Technology and Management, Geneva, Vol. 5, Iss. 1 ; pp. 90.

Jia-zhen, H.; Jian-jun, Z.; Jin, Z. (2007), “Influence of Overstock Risk on Buy Back Strategy in Supply Chain",Wireless Communications, Networking and Mobile Computing, WiCom. International Conference on, 21-25 Sept., pp 4657 - 4661.

Joseph, Anthony; Larrain, Maurice; Singh, Eshwar (2008), “Forecasting Real inventories and the anomaly of money illusion", Business Economics, Vol 43, Jan, No 1.

Katz, J. (2006), “Be Flexible”, Industry Week, Cleveland, Vol. 255, Iss. 9, Sept, p. 14.

Lapide, L. (2008), "How Buffers Can Mitigate Risk", Supply Chain Management Review. New York, Apr, Vol. 12, Iss. 4, pp. 6, 1 pgs.

Lusa, A. ; Corominas, A. and Muñoz, N. (2008), “A multistage scenario optimisation procedure to plan annualised working hours under demand uncertainty", International Journal of Production Economics, Amsterdam, Jun, Vol. 113, Iss. 2, pp. 957.

Marvel, H. P. and Wang, H. (2007), “A generic approach to measuring the machine flexibility of manufacturing systems Inventories, Manufacturer Returns Policies, and Equilibrium Price Dispersion under Demand Uncertainty", Journal of Economics \& Management Strategy, Cambridge, Winter, Vol. 16, Iss. 4, pp. 1031.

Matuyama, K.; Sumita, T. and Wakayama, D. (2009), “Periodic forecast and feedback to maintain target inventory level", International Journal of Production Economics, Amsterdam, Mar, Vol. 118, Iss. 1, pp. 298.

Moole, B. R. and Korrapati, R. B. K. (2004), “A Decision Support System Model for Forecasting in Inventory Management using Probabilistic Multidimensional Data Model (PMDDM)", Allied Academies International Conference. Academy of Information and Management Sciences. Proceedings. Cullowhee, Vol. 8, Iss. 2, pp. 35, 6 pgs.

Mukhopadhyay, S. K. and Ma, H. (2009), “Joint procurement and production decisions in remanufacturing under quality and demand uncertainty", International Journal of Production Economics, Amsterdam, Jul, Vol. 120, Iss. 1; pp. 5.

Pearson, M. (2003), “An equilibrium solution to supply chain synchronization", Centre for Mathematics and Statistics, Management School, Napier University, Edinburgh, EH11 
4BN, UK IMA Journal of Management Mathematics, 14(3), pp.165-185.

Pindyck, R. S. (1988), “Irreversible Investment, Capacity Choice, and the Value of the Firm", The American Economic Review, Vol. 78, No. 5, pp. 969-985.

Ryu, Seung-Jin; Tsukishima, T.; Onari, H. (2009), “A study on evaluation of demand information-sharing methods in supply chain", International Journal of Production Economics, Amsterdam, Jul, Vol. 120, Iss. 1, pp. 162.

Sengupta, S. (2004), "The top 10 supply chain mistakes", Supply Chain Management Review, New York, Vol. 8, Iss. 5, Jul/ Aug, pp. 42.

Sheffi, Y. (2001), "Supply Chain Management Under The Threat of International Terrorism", The International Journal of Logistics Management, 12, 2, pp. 1-11.

Sodhi, ManMohan S. and Tang, C. S. (2009), "Modeling supplychain planning under demand uncertainty using stochastic programming: A survey motivated by asset-liability management", International Journal of Production Economics, Amsterdam, Oct, Vol. 121, Iss. 2, pp. 728.

Song, Dong-Ping (2008), "Stability and optimization of a production inventory system under prioritized base-stock control", International Shipping \& Logistics Group, The Business School, University of Plymouth, UK.

Song, Jing-Sheng; Zhang, H.; Hou, Y. and Wang, M. (2010), “The Effect of Lead Time and Demand Uncertainties in (r, q) In- ventory Systems", Operations Research. Linthicum, Jan/Feb, Vol. 58, Iss. 1, pp. 68, 16 pgs.

Stalk, G. (2008), "Confronting the Growing Supply Chain Crisis", Business Finance, Loveland, Vol. 14, Iss. 6, Jun, pp. 28-29.

Tan, T. (2008), “Using Imperfect Advance Demand Information in Forecasting", Department of Technology Management, Eindhoven University of Technology, IMA Journal of Management Mathematics Advance, February 16.

Tan, T.; Güllü, R., (2009), " Using imperfect advance demand information in ordering and rationing decisions", Nesim Erkip. International Journal of Production Economics, Amsterdam, Oct, Vol. 121, Iss. 2, pp. 665.

Tannous, G.F. (1996), “Capital Budgeting for Volume Flexible Equipment”, Decision Sciences, 27, No. 2. pp. 157-184.

Walsh, P. M.; Williams, P. A. and Heavey, C. (2007), "Investigation of rolling horizon flexibility contracts in a supply chain under highly variable stochastic demand", Enterprise Engineering Research Group, Department of Manufacturing and Operations Engineering, University of Limerick, Ireland.

Wiersema, William H. (2008), “Conquering the inventory problem”, Electrical Apparatus, 61, 1. ABI/Inform, Jan, Pg 32-33.

Workman, J.; Scheidler, N. (2009),"Safety stock: everybody wants to use, nobody wants to own", The Journal of Business Forecasting, Flushing: Fall, Vol. 28, Iss. 3, p. 4 (4 pages).

\section{AUTHOR'S BIOGRAPHY}

Rui Fernandes is graduated in accountant and administration, he teaches in management control areas at ESEIG since 2002. He has been collaborating in many seminars with Institute for International Research. Actually he is a PhD student in industrial management at Aveiro University, head of management control curriculum unit of the Master in Finance at ESEIG, CFO at Amorim Revestimentos SA, board member at Amorim Revestimientos SA, Amorim Cork GmbH, Amorim Cork Distribution Netherlands BV and Amorim Japan Corporation.

Joaquim B. Gouveia PhD in 1983 and Aggregate in Electrotechnical and Computer Engineering. Full Professor at Department of Economics, Management and Industrial Engineering of University of Aveiro, since Oct. 2001. He is also member of the Board of GALP ENERGIA, SGPS, S.A., since May of 2008, president and founder of the Executive Board of ENERGAIA, since Jun 1999. He has been involved in several National and European projects, taking leaderships of a lot of them. His main research areas of interests are in Energy Management. Energy Policy, Energy Efficiency, Power System Management, Innovation and Technology Management, Supply Chain Management, Services Operations, Networks \& Collaborative Work.

Carlos Pinho Ph.D. in Applied Economics from the University of Santiago de Compostela and Finance Master Degree from the University Portucalense. He is assistant Professor at Department of Economics, Management and Industrial Engineering of University of Aveiro. He is also Director of the Doctorate in Accounting and Course Director of Master in Economics. His main research areas of interests are in the field of Real Options and Financial Markets Monetary and Derivatives Markets. 